\title{
An Architectural Analysis of Pear Cultivars Grown under South African Conditions and the Relevance to Local Maintenance Pruning Strategies
}

\author{
Nigel C. Cook \\ Department of Horticultural Science \\ University of Stellenbosch \\ Private Bag X1, Matieland, 7602 \\ South Africa
}

Pierre Du Plooy

Du Toit group

PO Box 236, Cere, 6835

South Africa

\begin{abstract}
To quantify the growth habit of locally important pear varieties, initially, 2-year-old pear branches were classified into groups based on the length and position of lateral shoots. Four groups were formed that ranged from cultivars with a spurred growth habit and strong apical control, to cultivars with a spreading growth habit and weak apical control. Secondly, the development of fruiting branches was observed for up to five years by observing the five developmental alternatives of the terminal buds of laterals, i.e., dormant, vegetative, reproductive without fruit, reproductive with fruit, and abortion. Under local conditions two general problems were observed.
\end{abstract}

A large proportion of buds remain vegetative giving rise to poor flowering, and many buds remain dormant, probably due to the use of vigorous rootstocks and inadequate winter chilling. Local training systems address these shortcomings through the use of rest-breaking agents, girdling, and winter pruning techniques. Winter pruning strategies for locally important cultivars can be split into two broad approaches. In one approach spurs are renewed within spur systems primarily via bourse shoots. In the other approach spurs are renewed via year-old shoots. The motivation for the use of these systems is discussed in light of the above architectural findings.

Keywords: Pyrus communis, branching, fruiting habit, winter pruning

\section{INTRODUCTION}

Pruning strategies usually distinguish between technologies aimed at creating structure, i.e., training, and those aimed at maintaining the vitality and productivity of fruiting wood, i.e., maintenance pruning. Pear branches do respond to certain pruning manipulations in a predictable manner (Saunders et al., 1991; Wertheim, 1990), however, due to the large impact of local climatic effects pruning strategies are often largely based on local experience with specific cultivars (Sansavini and Musacchi, 1994).

To understand the ontogenic development of fruiting structures or fruiting habit at the cultivar level, we needed to understand genotypic difference in branch development. The branching habit determines the structure of the fruiting branch subunits, i.e., the positional distribution of spurs, brindles, and long shoots. To describe fruiting habit, we thereafter quantified the development of these subunits over time according to the method developed in apple by Lauri et al. (1995).

In this communication we review our observations of the development of fruiting branches as it occurs under South African conditions. This is used to describe the rationale of local maintenance pruning strategies. 


\section{BRANCHING HABIT}

Branching in pear is proleptic (from dormant buds) and acrotonic (from distal buds), and is at least partially controlled by apical dominance (the control of the distal buds and shoot tissues over lateral budburst), and the apical control exerted by the terminal extension growth over the growth of lateral shoots in terms of length and orientation. Apical control is understood to be strong when the terminal extension growth checks the growth of the lateral shoots such that only spurs develop. Weak apical control occurs when lateral shoots successfully compete with the terminal extension growth, resulting in numerous equally strong distal extension shoots (Brown et al., 1967; Cook et al., 1999). A continuum from strong to weak apical control is observed between pear cultivars. Branching habit is a function of lateral shoot length relative to position on the axis (Rauh, 1939).

The length and position of lateral shoots on two-year-old branches of Flamingo, Forelle, Rosemarie, Abaté Fetel, Buerre D'Anjou, Packham's Triumph, and Golden Russet Bosc was quantified (Du Plooy et al., 2002b). Cluster analysis of shoot density in positional classes on upright branches resulted in the logical grouping of cultivars into four branching habit groupings (Fig. 1). It was possible to classify the pear cultivars used in this investigation into four branching habit groups, on the basis of length and position of one-year-old laterals on the twoyear-old axes of upright branches. The mean value for each quadrant $x$ length variable was plotted for each group as identified by the canonical discriminant analysis (Fig. 2).

Group 1, consisting only of 'Flamingo', displays a spurred branching habit (Fig. 1). Strong apical control is apparent from the dominance exerted by the terminal extension growth over the numerous spurs observed on the full length of the two-year-old axes. Group 4, consisting of 'Packham's Triumph' and 'Golden Russet Bosc', on the other extreme exhibit the weakest apical control. Numerous distally situated lateral buds develop into long shoots, their growth is apparently not as strongly checked by the terminal extension growth as in group 1 (Fig. 1). The expression of apical control by the terminal extension growth diminished from group 1 to 4 .

\section{FRUITING HABIT}

Lespinasse (1992) summarised the classification of apple cultivars into four fruiting types or ideotypes, on the basis of growth and fruiting habit. Lauri et al. (1995) quantified the bearing habits of apple trees belonging to these ideotypes, with emphasis on the phenomenon of biennial bearing. Using this method the bearing habit of non-pruned fruiting branches of seven pear cultivars was quantified according to the ontogenetic development from axillary buds, i.e., developmental changes in the terminal position of laterals on branches. Description started with the development of the main fruiting branch, forming several leaves in the first year of growth (designated Year Y), with meristems developing in the leaf axils.

In the following season (Year $Y+1$ ), these buds had five developmental alternatives: to remain as a latent bud (L), to develop vegetativly $(\mathrm{V})$, to flower without fruit set $(\mathrm{F})$, to flower and set fruit (P), or to abort and leave a scar (S). Each year the development of these buds was observed and classified anew, giving rise to sequences describing up to five years of development (Du Plooy et al., 2002a). The first step in the quantification of the bearing habits was to determine the year-to-year transitions for each cultivar. The three functional phases (L, $G$ and S) of lateral development for apple were observed in pear. From 44\% ('Beurre $D^{\prime}$ Anjou') to $79 \%$ ('Flamingo') of laterals remained in the growing phase $G(V, F$, and $P$ cumulatively) over two consecutive years. 
This coincided with relatively low proportions of buds remaining in the latent phase (L) or moving to the ending phase (S). Fig. 3 shows the proportion of bud states (L, V, F, P, and S) per year for each cultivar. The relatively low proportion of the $L$ and $S$ bud states are again apparent. The predominant bud type in the growing phase is $\mathrm{V}$, especially in the case of 'Golden Russet Bosc', Beurre D'Anjou' and 'Forelle'/BP1. Although flowering was generally low for all cultivars throughout the trial, 'Flamingo' and 'Abaté Fetel' went into the reproductive phase ( $F$ and $P$ ) in year $\mathrm{Y}+3$.

'Packham's Triumph' and 'Rosemarie' displayed a relatively high proportion of $\mathrm{F}$ and $\mathrm{P}$ buds in year $\mathrm{Y}+1$. This may be explained by the fact that most pear cultivars bear primarily on spurs, but some cultivars ('Packham's Triumph' and 'Rosemarie') have the ability to also bear fruit on one-year-old shoots. The occurrence of some $P$ buds in year $Y+1$, but mostly from year $Y+2$, in the case of Forelle'/QA, is probably due to the precocity enhancing effect of the dwarfing Quince A rootstock on 'Forelle' (Du Plooy and Van Huyssteen, 2000). Comparing 'Forelle'/QA and 'Forelle'/BP1, it is interesting to note that a larger proportion of buds remained latent in the case of the dwarfing QA rootstock (Table 1). Growth on QA rootstock was less vigorous.

Fig. 4 displays bud state transitions observed between successive years within the growing phase (G). The transition most frequently observed was VV, which corresponds to results in Fig. 3, confirming the vegetative nature of the cultivars in this study. The combination PP denotes the bourse-over-bourse bearing phenomenon. This phenomenon was observed in the cultivars Packham's Triumph, Rosemarie and to a lesser extent in Forelle/QA and corresponds to the ability of these culivars to bear fruit terminally on bourse shoots. For these cultivars the laterals exhibit more functional autonomy (Lauri et al., 1995).

Spur autonomy in apple is associated with an extinction mechanism (abortion of weak reproductive structures), and enhanced allocation to more autonomous reproductive structures (Lauri et al., 1995). In the studied pear cultivars, the occurrence of this extinction mechanism was low compared to apple, possibly due to lower spur autonomy and a more spurred growth habit of pears. In the pear cultivars 'Packham's Triumph' and 'Rosemarie' where some spur autonomy was observed (PP; Fig. 4), the higher proportion of latency and reduced number of growing buds could increase the allocation of assimilates to the fruiting structures.

Most cultivars in this study were predominantly in a vegetative state due to a lack of flower formation (Figs 3 and 4). The vegetative growth to fruiting balance for these cultivars needs to be shifted in favour of fruiting. The cultivars Packham's Triumph, Rosemarie, and Forelle on QA rootstock are more precocious locally. Although the occurrence of the extinction mechanism was generally low, the higher bud latency may increase allocation to fruiting structures. This, in combination with the tendency of cultivars such as Packham's Triumph and Rosemarie to develop longer, more autonomous shoots, may explain their higher productivity.

Cultural practices that reduce vigour such as training branches to the horizontal, ringing and scoring, and regulated deficit irrigation are used to enhance flowering and lead to a more favorable vegetative growth to fruiting relationship.

\section{REST BREAKING}

Winter chilling is limited locally, necessitating the use of rest-breaking agents. Currently our industry relies primarily on the use of mineral oil alone or in combination with Dormex ${ }^{\circledR}$ at the rates presented in Table 1 . The decision as to what agent to use and the rate is based on the chilling requirement of the target cultivar and the winter chilling received. 


\section{MAINTENANCE PRUNING STRATEGIES}

Winter pruning strategies for locally important cultivars can be split into two broad approaches, largely determined by the branching and fruiting habit. The traditionally grown 'Williams' and 'Packham's Triumph' pears are both "tip-bearing" cultivars and pruning is largely based on a renewal system where new spurs are continually developed from year-old shoots.

Year-old shoots are left a year to spur up before being cut back into the "ring" or deeper into the flower bud bearing spurs on the 2-year-old wood (Fig. 5A). This "ring cut" is well known to increase fruit set (Saunders et al., 1990). Thereafter, "old" fruiting units are cut back hard to rejuvenate year-old shoots. Locally most "tip-bearing" cultivars, i.e., those in groups 3 and 4 (Fig. $1)$, are maintained in this way.

The spur types, i.e., groups 1 and 2, are managed separately. In these varieties, primarily 'Forelle' locally, spurs are renewed within spur systems primarily via bourse shoots. All year-old shoots on the fruiting branch are removed annually, either during summer or winter (Fig. 5B). Older more complex spur systems are sometimes thinned (spur thinning). 


\section{LITERATURE CITED}

- Brown, C.L., McAlpine, R.G. and Kormanik, P.P. 1967. Apical dominance and form in woody plants: a reappraisal. Amer. J. Bot. 54:153-162.

- Cook, N.C., Rabe, E. and Jacobs, G. 1999. Early expression of apical control regulates length and crotch angle of sylleptic shoots in Peach and Nectarine. HortScience 34:604-606.

- Du Plooy, P. and Van Huyssteen, P. 2000. Effect of BP1, BP3 and Quince A rootstocks, at three planting densities, on precocity and fruit quality of 'Forelle' pear (Pyrus communis L.). S. Afr. J. Plant Soil 17:57-59.

- Du Plooy, P., Jacobs, G. and Cook, N.C. 2002a. Quantification of bearing habit on the basis of lateral bud growth of seven pear cultivars grown under conditions of inadequate winter chilling in South Africa. Scientia Hort. 95:185-192.

- Du Plooy, P., Sadie, A., Jacobs, G. and Cook, N.C. 2002b. Branching habit of two-yearold pear branches classified on the basis of length and position of one year-old laterals. Scientia Hort. 95:193-201.

- Lauri, P.É., Térouanne, E., Lespinasse, J.M., Regnard, J.L. and Kelner, J.J. 1995. Genotypic differences in the axillary bud growth and fruiting pattern of apple fruiting branches over several years: An approach to regulation of fruit bearing. Scientia Hort. 64:265-281.

- Lespinasse, Y. 1992. Breeding apple tree: aims and methods. p.103-110. In: F. RousselleBourgeois and P. Rousselle (eds.), Proc. Joint Conf. of the EAPR Breeding and Varietal Assessment Section and the EUCARPIA Potato Section, January 1992, Landerneau, France. INRA, Ploudaniel, France.

- Rauh, W. 1939. Über Gesetzmäßigkeit der Verzweiging und deren Bedeutung für die Wuchsformen der Pflanzen. Mitt. Dtsch. Dendr. Ges. 52:86-111.

- Sansavini, S. and Musacchi, S. 1994. Canopy architecture, training and pruning in the modern European pear orchards: an overview. Acta Hort. 367:152-165.

- Saunders, R.C., Jacobs, G. and Strydom, D.K. 1991. Effect of pruning on fruitset and shoot growth of 'Packham's Triumph' pear trees. Scientia Hort. 47:239-245.

- Wertheim, S.J. 1990. De Peer. Mededeling van het proefstation voor de fruitteelt no. 22. Wilhelminadorp.

\section{Tables}

Table 1. Current industry rest-breaking recommendations for pears.

\begin{tabular}{lcccccc}
\hline $\begin{array}{l}\text { Cultivar chilling } \\
\text { requirement }\end{array}$ & \multicolumn{2}{c}{ High } & \multicolumn{2}{c}{ Medium } & \multicolumn{2}{c}{ Low } \\
\hline Chill units received & $>800$ & $<500$ & $>800$ & $<500$ & $>800$ & $<500$ \\
\hline Oil rate & - & - & $4-6 \%$ & $5-6 \%$ & $4-6 \%$ & $5-6 \%$ \\
\hline Dormex ${ }^{\circledR}+$ & $0.5 \%+$ & $0.5 \%+$ & $0.5 \%+$ & $0.5 \%+$ & $0.5 \%+$ & $0.5 \%+$ \\
Oil rate & $2 \%$ & $3-4 \%$ & $2 \%$ & $2-3 \%$ & $2 \%$ & $2-3 \%$ \\
\hline
\end{tabular}




\section{Figures}

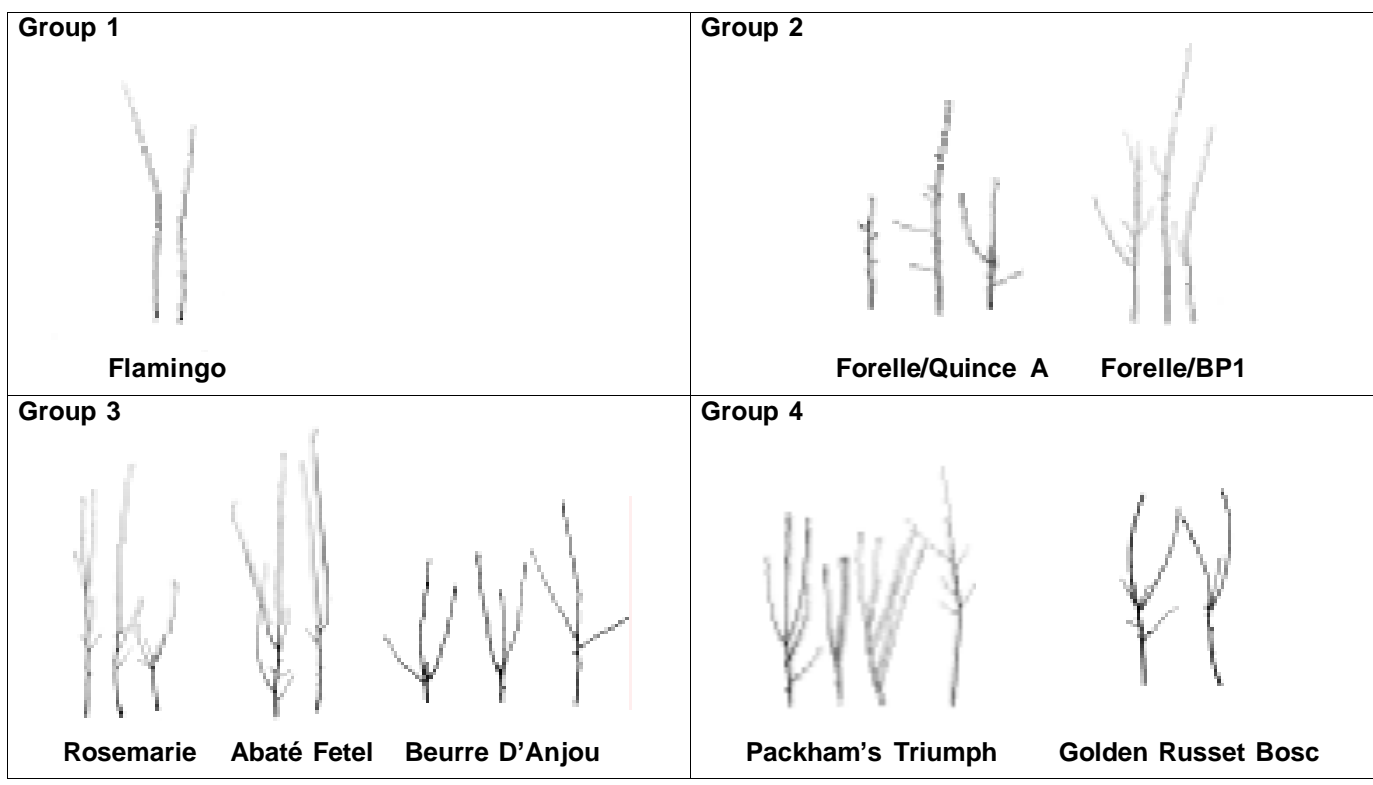

Fig. 1. Examples of upright, two-year-old pear branches showing cultivar differences in branching habit classified into four branching habit groups by cluster analysis of the cultivar mean shoot density per length by position class (Du Plooy et al., 2002b).

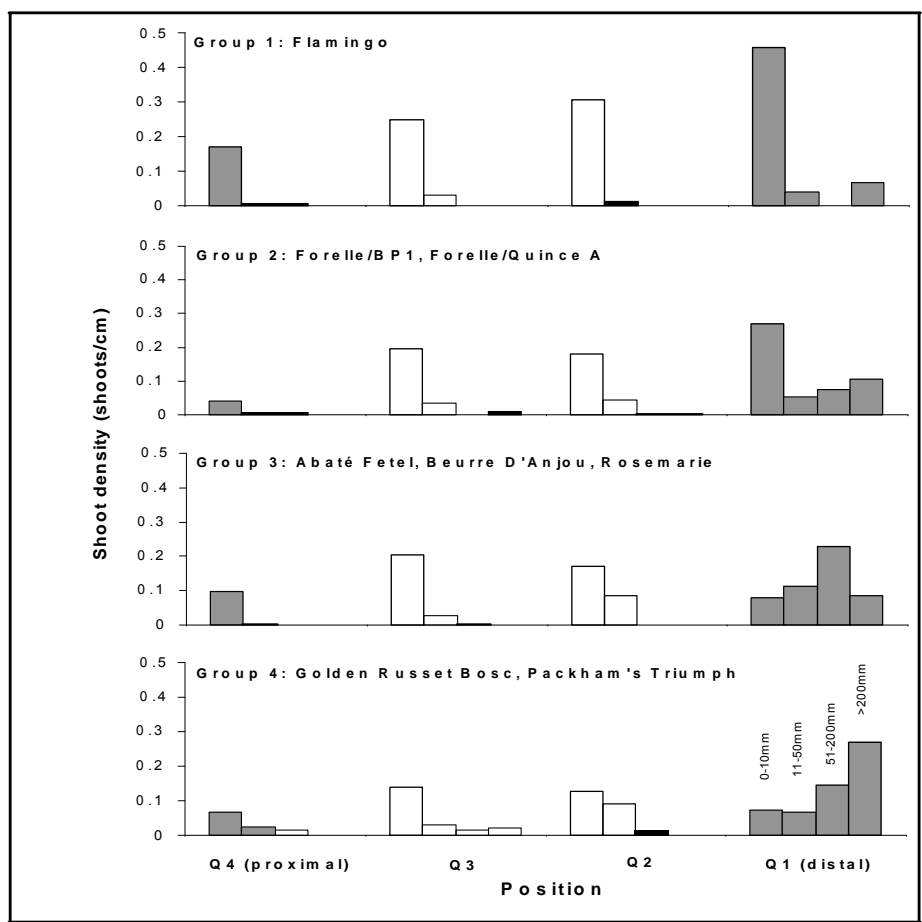

Fig. 2. Shoot density of each length by position class for the four branching habit groups.

Shaded parameters account for $42.5 \%$ of the correlation between branches and their grouping (Du Plooy et al., 2002b). 


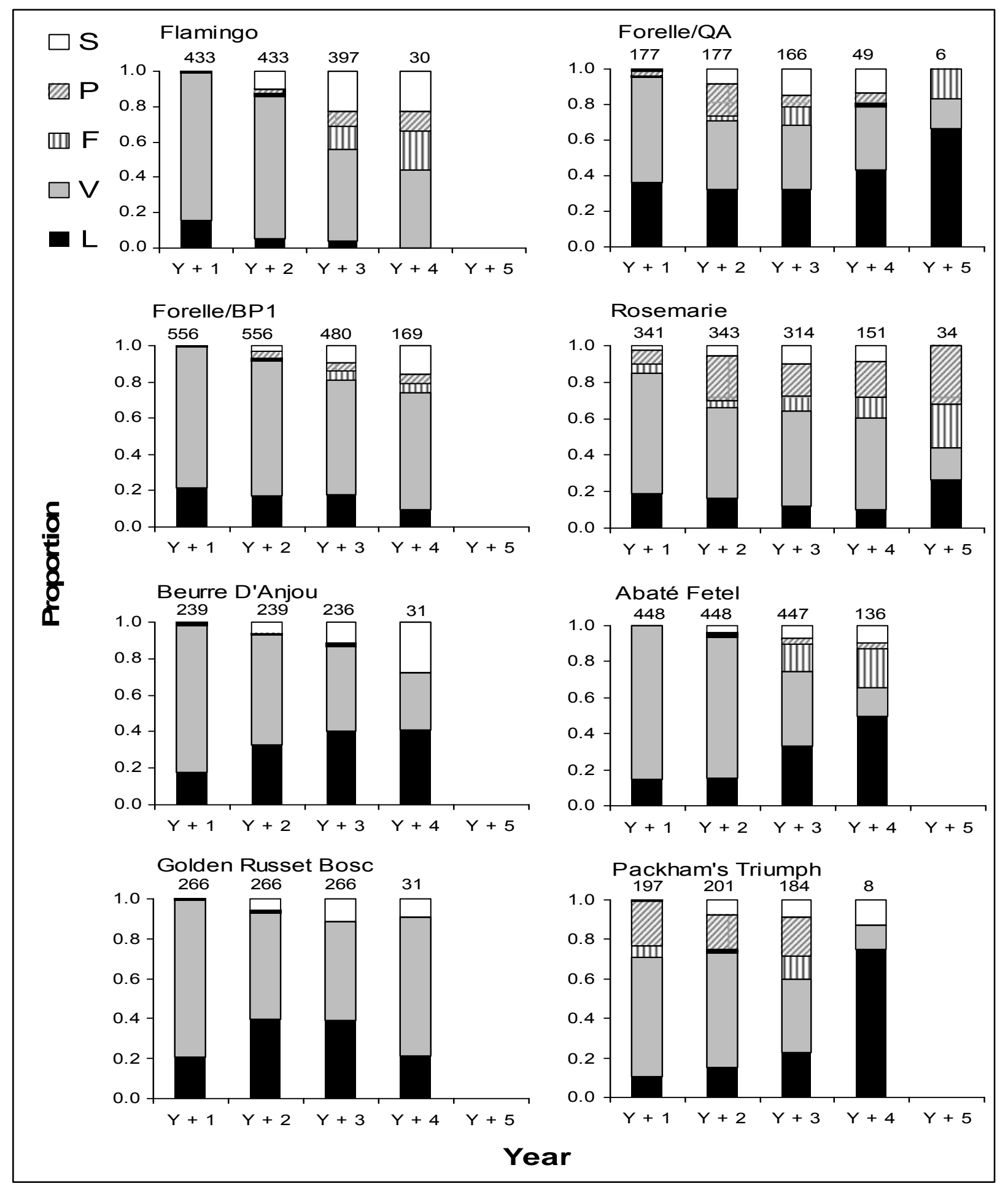

Fig. 3. Proportion of bud states observed in the terminal positions of laterals on fruiting branches for each cultivar. The bud states observed were latent buds (L), vegetative buds (V), flower buds without fruit $(F)$, flower buds producing fruit $(P)$, and aborted buds $(S)$. The total number of sequences $(n)$ in each year is indicated above each bar (Du Plooy et al., 2002a). 


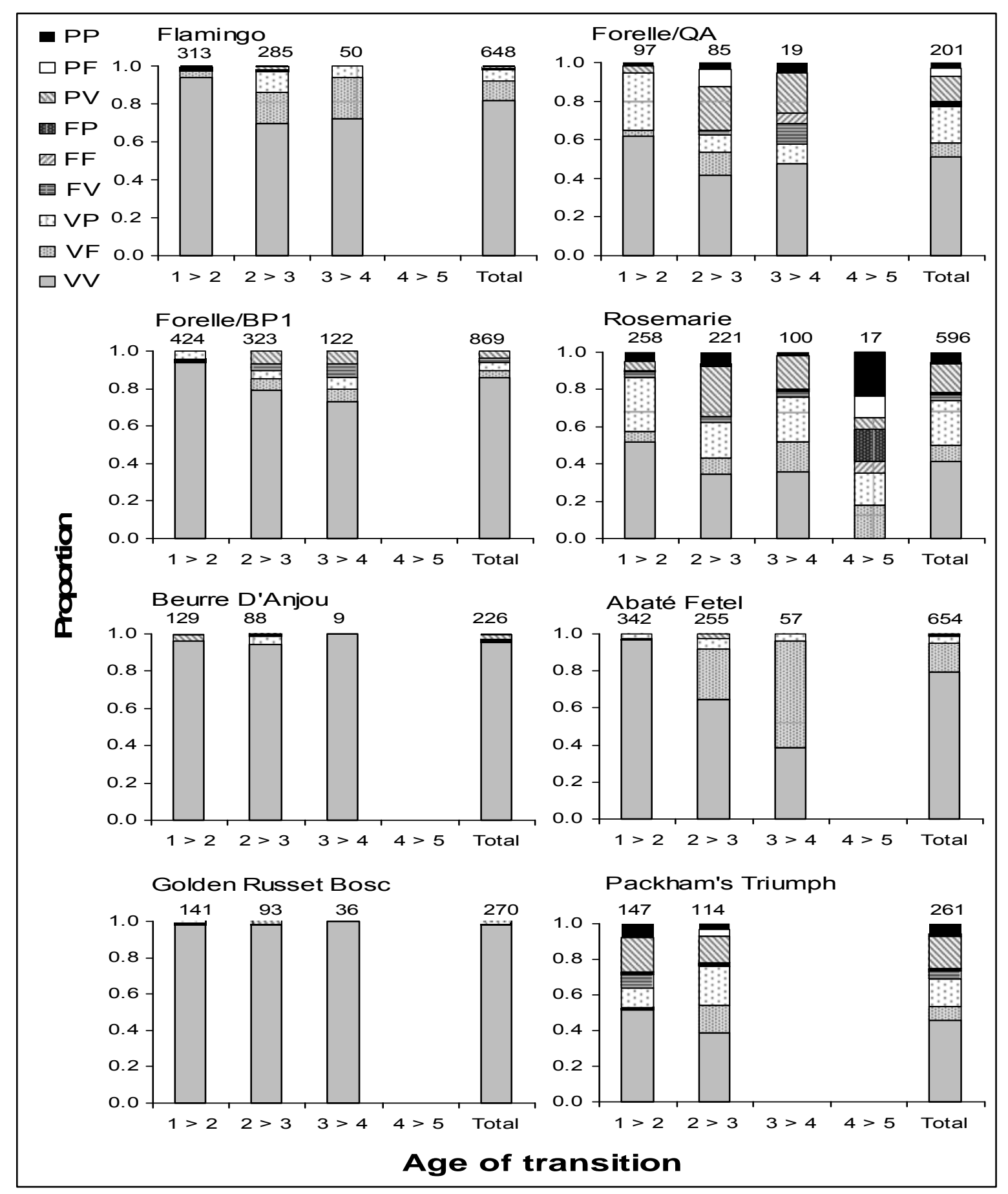

Fig. 4. Proportion of the different year-to-year bud type transitions of laterals on fruiting branches observed in the growing phase for each cultivar. All combinations of vegetative buds $(\mathrm{V})$, flower buds without fruit $(\mathrm{F})$ and flower buds producing fruit $(\mathrm{P})$ occurring in the growing phase are shown. The total number of sequences $(n)$ in each year is indicated above each bar (Du Plooy et al., 2002a). 


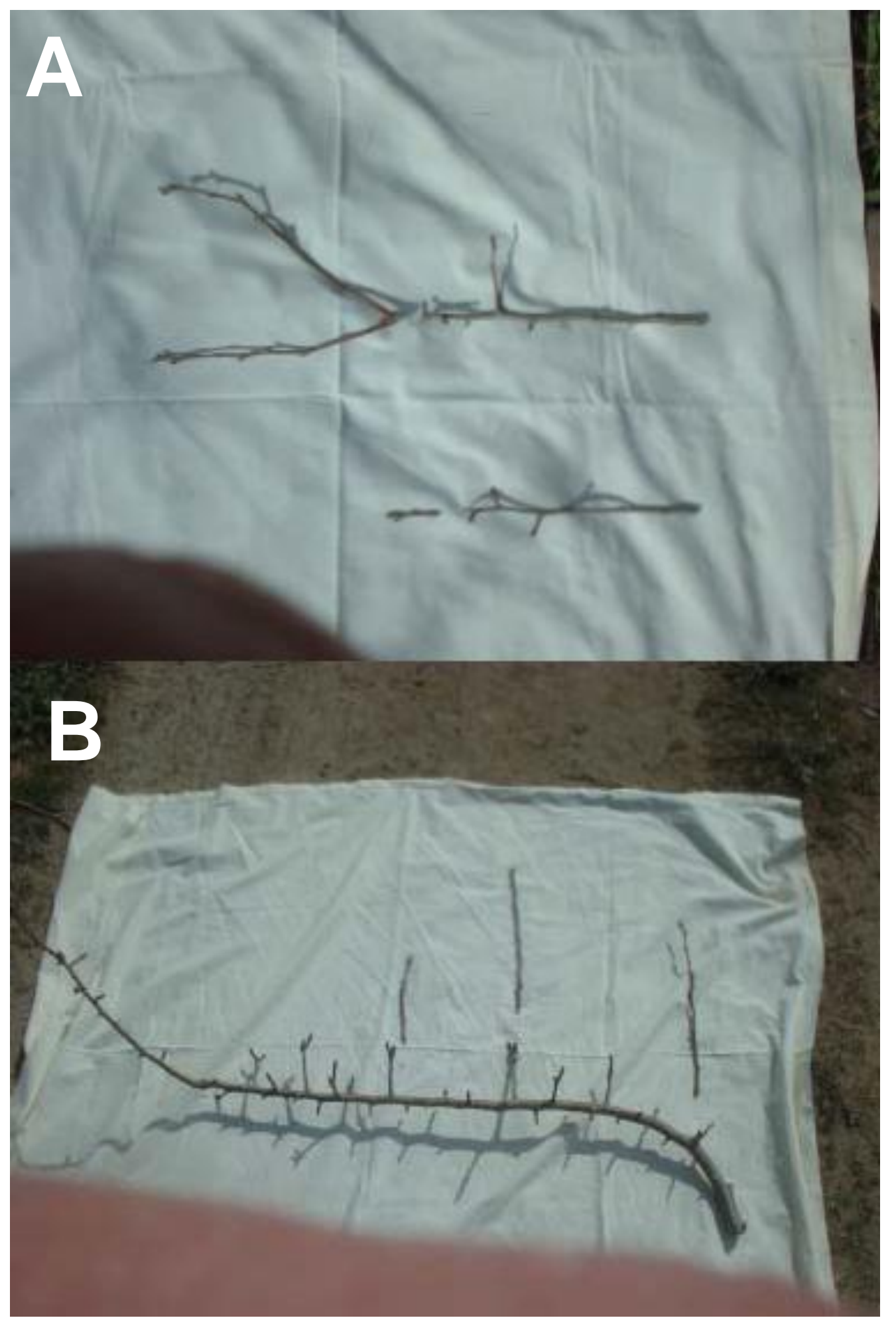

Fig. 5. Maintenance pruning cuts generaly used in South African pear training systems. In "tipbearing" the "ring cut" is made to 2-year-old spurred up branches to enhance fruitset (A). In "spur types" all year-old shoots are annually removed (B). 